\title{
Medical Costs of Oral Anticoagulants vs Warfarin for Atrial Fibrillation Patients with Different Stroke Risks
}

Steve Deitelzweig • Alpesh Amin • Yonghua Jing • Dinara Makenbaeva •

Daniel Wiederkehr $\cdot$ Jay Lin $\cdot$ John Graham

To view enhanced content go to www.cardiologytherapy-open.com

Received: July 1, 2013 / Published online: August 17, 2013

(C) The Author(s) 2013. This article is published with open access at Springerlink.com

\section{ABSTRACT}

Introduction: The Apixaban for the Reduction in Stroke and Other Thromboembolic Events in Atrial Fibrillation (ARISTOTLE), Randomized Evaluation of Long-term Anticoagulation Therapy (RE-LY), and Rivaroxaban Once Daily Oral Direct Factor Xa Inhibition Compared with Vitamin K Antagonism for Prevention of Stroke and Embolism Trial in Atrial Fibrillation (ROCKET-AF) trials demonstrated that the oral

S. Deitelzweig $(\varangle)$

Ochsner Medical Center, New Orleans, LA, USA

e-mail: sdeitelzweig@ochsner.org

A. Amin

University of California, Irvine, CA, USA

Y. Jing · D. Makenbaeva · J. Graham

Bristol-Myers Squibb, Plainsboro, NJ, USA

D. Wiederkehr

Pfizer, New York City, NY, USA

J. Lin

Novosys Health, Flemington, NJ, USA

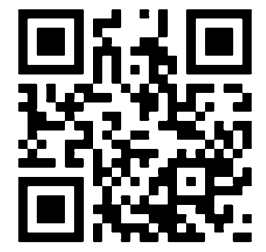

Enhanced content for this article is

available on the journal web site:

www.cardiologytherapy-open.com anticoagulants (OACs), apixaban, dabigatran, and rivaroxaban, respectively, are efficacious for stroke prevention among nonvalvular atrial fibrillation (NVAF) patients. Based on clinical trial results this study evaluated medical costs of clinical events associated with use of individual OACs relative to those of warfarin in NVAF patients with moderate and high stroke risk.

Methods: Rates for primary and secondary efficacy and safety outcomes (i.e., clinical events) among NVAF patients with $\mathrm{CHADS}_{2}=2$ and $\geq 3$ were determined from the three OAC trials. One-year incremental costs among patients with clinical events from a US payer perspective were obtained from the literature and inflation adjusted to 2010 costs. Medical costs for clinical events associated with each OAC vs. warfarin were estimated and compared.

Results: For NVAF patients with moderate stroke risk $\left(\mathrm{CHADS}_{2}=2\right)$ differences in clinical event medical costs vs. warfarin were $-\$ 298$, $-\$ 143$, and $+\$ 117$ per patient year for apixaban, dabigatran (150 $\mathrm{mg})$, and rivaroxaban, respectively (negative numbers indicate cost reduction). For NVAF patients with high stroke risk $\left(\mathrm{CHADS}_{2} \geq 3\right)$ differences in clinical event 
medical costs vs. warfarin were $-\$ 697,+\$ 2$, and $-\$ 100$ for apixaban, dabigatran (150 mg), and rivaroxaban, respectively.

Conclusions: Medical cost differences associated with OACs vs. warfarin vary according to stroke risk. Of the three OACs, apixaban demonstrated consistent medical cost reductions vs. warfarin for NVAF patients with moderate and high stroke risks.

Keywords: Apixaban; Atrial fibrillation; Dabigatran; Stroke prevention; Oral anticoagulants; Rivaroxaban

\section{INTRODUCTION}

Nonvalvular atrial fibrillation (NVAF) is a cardiac rhythm disorder, which increases stroke risk approximately fivefold and affects $>5$ million Americans [1, 2]. Warfarin is efficacious for reducing stroke risk among NVAF patients, but its use has limitations, including a narrow therapeutic range, significant drug-drug interactions, and an increased risk for major bleeding events, all of which can be exacerbated for those with comorbidities and/or who are $\geq 75$ years of age [3, 4]. The Apixaban for the Reduction in Stroke and Other Thromboembolic Events in Atrial Fibrillation (ARISTOTLE), Randomized Evaluation of Long-term Anticoagulation Therapy (RE-LY), and Rivaroxaban Once Daily Oral Direct Factor Xa Inhibition Compared with Vitamin K Antagonism for Prevention of Stroke and Embolism Trial in Atrial Fibrillation (ROCKET-AF) trials demonstrated that the oral anticoagulants (OACs), apixaban, dabigatran (150 $\mathrm{mg})$, and rivaroxaban, respectively, are at least as efficacious as warfarin for stroke prevention among NVAF patients [5-7]. NVAF patients included in these trials differed in stroke risk from those in the ROCKET-AF trial in having a mean $\mathrm{CHADS}_{2}$ score of 3.5 , while those included in the other trials had mean $\mathrm{CHADS}_{2}$ scores of 2.1 [5-7]. Medical costs for clinical events among the overall NVAF population using any of the OACs vs. warfarin were estimated to be lower [8]. However, these results may differ for patients with different stroke risks. This study compared medical costs for clinical events of NVAF patients in the OAC vs. warfarin trials with moderate $\left(\mathrm{CHADS}_{2}=2\right.$ ) and higher stroke risk $\left(\mathrm{CHADS}_{2} \geq 3\right)$ treated with individual OACs vs. warfarin from a US payer perspective.

\section{MATERIALS AND METHODS}

Clinical event rates (stroke/systemic embolism (SSE), myocardial infarction (MI), pulmonary embolism/deep vein thrombosis (PE/DVT), major bleeding events excluding hemorrhagic stroke (MBEHS), non-major bleeding events) among NVAF patients with $\mathrm{CHADS}_{2}=2$ and $\geq 3$ treated with individual OACs or warfarin were determined from the three OAC trials [5-7] (Table 1). Hemorrhagic stroke (HS) was considered as an efficacy and safety end point in the OAC vs. warfarin trials. To avoid costing twice, HS events were excluded from major bleeding events, but kept grouped with SSE. MBEHS rate was defined as the absolute event rate of major bleeding events minus HS. When the event rate for a particular clinical event was not reported in a clinical trial, the rate of an end point containing this clinical event was used [8]. The event rates of non-major bleeding events, including clinically relevant non-major bleeding events and other minor bleeding events, were not reported by stroke risk groups in the original clinical trial publications. In this analysis we assumed the relative risks of these non-major bleeding events 
Table 1 Estimated absolute risks for clinical events among NVAF patients at moderate and high stroke risk

\begin{tabular}{|c|c|c|c|c|c|c|c|c|c|c|c|c|}
\hline \multirow{3}{*}{$\begin{array}{l}\text { Trial } \\
\text { Drug } \\
\text { CHADS }_{2}\end{array}$} & \multicolumn{4}{|c|}{ ARISTOTLE } & \multicolumn{4}{|c|}{ RE-LY } & \multicolumn{4}{|c|}{ ROCKET-AF } \\
\hline & \multicolumn{2}{|c|}{$\begin{array}{l}\text { Warfarin } \\
\text { (\%/patient-year) }\end{array}$} & \multicolumn{2}{|c|}{$\begin{array}{l}\text { Apixaban } \\
\text { (\%/patient-year) }\end{array}$} & \multicolumn{2}{|c|}{$\begin{array}{l}\text { Warfarin } \\
\text { (\%/patient-year) }\end{array}$} & \multicolumn{2}{|c|}{$\begin{array}{l}\text { Dabigatran } \\
\text { (\%/patient-year) }\end{array}$} & \multicolumn{2}{|c|}{$\begin{array}{l}\text { Warfarin } \\
\text { (\%/patient-year) }\end{array}$} & \multicolumn{2}{|c|}{$\begin{array}{l}\text { Rivaroxaban } \\
\text { (\%/patient-year) }\end{array}$} \\
\hline & $=2$ & $\geq 3$ & $=2$ & $\geq 3$ & $=2$ & $\geq 3$ & $=2$ & $\geq 3$ & $=2$ & $\geq 3$ & $=2$ & $\geq 3$ \\
\hline SSE & 1.40 & 2.80 & 1.20 & 1.90 & 1.38 & 2.68 & 0.84 & 1.88 & 2.15 & 2.44 & 1.79 & 2.15 \\
\hline $\mathrm{MI}^{\mathrm{a}}$ & 0.61 & 0.61 & 0.53 & 0.53 & 0.53 & 0.53 & 0.74 & 0.74 & 1.12 & 1.12 & 0.91 & 0.91 \\
\hline $\mathrm{PE} / \mathrm{DVT}^{\mathrm{a}}$ & 0.05 & 0.05 & 0.04 & 0.04 & 0.09 & 0.09 & 0.15 & 0.15 & NR & NR & NR & NR \\
\hline MBEHS & 2.59 & 3.39 & 2.08 & 2.55 & 3.00 & 4.01 & 2.97 & 4.69 & 3.29 & 2.85 & 4.26 & 3.13 \\
\hline $\begin{array}{l}\text { Non-major } \\
\text { bleeding events }{ }^{b}\end{array}$ & 22.71 & 22.71 & 17.41 & 15.68 & 16.37 & 16.37 & 15.03 & 17.26 & 13.43 & 13.43 & 16.31 & 13.87 \\
\hline
\end{tabular}

ARISTOTLE apixaban for the reduction in stroke and other thromboembolic events in atrial fibrillation, $M B E H S$ major bleeding events excluding hemorrhagic stroke, $M I$ myocardial infarction, $N R$ not reported, $N V A F$ nonvalvular atrial fibrillation, $P E / D V T$ pulmonary embolism/deep vein thrombosis, $R E-L Y$ randomized evaluation of long-term anticoagulation therapy, ROCKET-AF rivaroxaban once daily oral direct factor $\mathrm{Xa}$ inhibition compared with vitamin $\mathrm{K}$ antagonism for prevention of stroke and embolism trial in atrial fibrillation

a Rates of MI and PE/DVT were not reported by $\mathrm{CHADS}_{2}$ score and those from the overall trial population were used [8]

b Relative risks of non-major bleeding events were assumed to be the same as major bleeding events in each trial, and these in combination with absolute event rates of non-major bleeding events from the overall trial populations were used for estimations of event rates

for NVAF patients with different stroke risks to be the same as those for major bleeding events reported for each trial. These estimated relative risks of non-major bleeding events in combination with the absolute event rates of non-major bleeding events from the overall trial population were used to estimate the event rates of non-major bleeding events for the stroke risk groups. The event rates of the secondary end points, MI, and PE/DVT were assumed to be the same as those of the overall trial population since such stroke risk group-specific data were not reported in the OAC vs. warfarin clinical trials.

One-year incremental costs (US payer perspective) for clinical events were obtained and adjusted to 2010 costs $[8,9]$. Based on the absolute risks for each of the clinical events, differences in medical costs associated with each OAC vs. warfarin were determined. Drug costs and monitoring expenses were not evaluated.
We additionally carried out a sensitivity analysis in which rates of clinical events for warfarin-treated NVAF patients were estimated as weighted averages from the three OAC trials by patient count. The absolute risks of events associated with OACs were derived by applying trial relative risks to the weighted average of warfarin event rates producing event rate estimates for each OAC for NVAF patients with $\mathrm{CHADS}_{2}=2$ and $\mathrm{CHADS}_{2} \geq 3$.

The authors conformed to the Helsinki Declaration of 1975, as revised in 2000 concerning human and animal rights, and Springer's policy concerning informed consent has been followed.

\section{RESULTS}

One-year medical costs of clinical events were as follows: $\mathrm{SSE}=\$ 40,613[10,11], \mathrm{MI}=\$ 37,446$ [12], $\mathrm{PE} / \mathrm{DVT}=\$ 19,532$ [13], MBEHS $=\$ 34,617$ 
Table 2 Estimated differences in medical costs for clinical events among NVAF patients at moderate and high stroke risk

\begin{tabular}{|c|c|c|c|c|c|c|}
\hline \multirow{3}{*}{$\begin{array}{l}\text { Trial } \\
\text { Drug } \\
\text { CHADS }_{2}\end{array}$} & \multirow{2}{*}{\multicolumn{2}{|c|}{$\frac{\text { ARISTOTLE }}{\text { Apixaban (\$/patient-year) }}$}} & \multirow{2}{*}{\multicolumn{2}{|c|}{$\frac{\text { RE-LY }}{\text { Dabigatran (\$/patient-year) }}$}} & \multirow{2}{*}{\multicolumn{2}{|c|}{$\frac{\text { ROCKET-AF }}{\text { Rivaroxaban (\$/patient-year) }}$}} \\
\hline & & & & & & \\
\hline & $=2$ & $\geq 3$ & $=2$ & $\geq 3$ & $=2$ & $\geq 3$ \\
\hline SSE & $-\$ 81$ & $-\$ 366$ & $-\$ 219$ & $-\$ 325$ & $-\$ 143$ & $-\$ 119$ \\
\hline MI & $-\$ 30$ & $-\$ 30$ & $\$ 79$ & $\$ 79$ & $-\$ 79$ & $-\$ 79$ \\
\hline $\mathrm{PE} / \mathrm{DVT}$ & $-\$ 2$ & $-\$ 2$ & $\$ 12$ & $\$ 12$ & NR & NR \\
\hline MBEHS & $-\$ 178$ & $-\$ 290$ & $-\$ 13$ & $\$ 236$ & $\$ 334$ & $\$ 97$ \\
\hline Non-major bleeding events & $-\$ 7$ & $-\$ 9$ & $-\$ 2$ & $\$ 1$ & $\$ 4$ & $\$ 1$ \\
\hline Total & $-\$ 298$ & $-\$ 697$ & $-\$ 143$ & $\$ 2$ & $\$ 117$ & $-\$ 100$ \\
\hline
\end{tabular}

ARISTOTLE apixaban for the reduction in stroke and other thromboembolic events in atrial fibrillation, $M B E H S$ major bleeding events excluding hemorrhagic stroke, $M I$ myocardial infarction, $N R$ not reported, $N V A F$ nonvalvular atrial fibrillation, $P E / D V T$ pulmonary embolism/deep vein thrombosis, $R E-L Y$ randomized evaluation of long-term anticoagulation therapy, $R O C K E T-A F$ rivaroxaban once daily oral direct factor $\mathrm{Xa}$ inhibition compared with vitamin $\mathrm{K}$ antagonism for prevention of stroke and embolism trial in atrial fibrillation

Table 3 Sensitivity analysis: estimated differences in medical costs for clinical events among NVAF patients at moderate and high stroke risk

\begin{tabular}{|c|c|c|c|c|c|c|}
\hline \multirow{3}{*}{$\begin{array}{l}\text { Trial } \\
\text { Drug } \\
\text { CHADS }_{2}\end{array}$} & \multirow{2}{*}{\multicolumn{2}{|c|}{$\frac{\text { ARISTOTLE }}{\text { Apixaban (\$/patient-year) }}$}} & \multirow{2}{*}{\multicolumn{2}{|c|}{$\frac{\text { RE-LY }}{\text { Dabigatran (\$/patient-year) }}$}} & \multirow{2}{*}{\multicolumn{2}{|c|}{$\frac{\text { ROCKET-AF }}{\text { Rivaroxaban (\$/patient-year) }}$}} \\
\hline & & & & & & \\
\hline & $=2$ & $\geq 3$ & $=2$ & $\geq 3$ & $=2$ & $\geq 3$ \\
\hline SSE & $-\$ 87$ & $-\$ 366$ & $-\$ 239$ & $-\$ 312$ & $-\$ 100$ & $-\$ 126$ \\
\hline MI & $-\$ 35$ & $-\$ 35$ & $\$ 79$ & $\$ 79$ & $-\$ 56$ & $-\$ 56$ \\
\hline PE/DVT & $-\$ 3$ & $-\$ 3$ & $\$ 8$ & $\$ 8$ & $-\$ 2$ & $-\$ 2$ \\
\hline MBEHS & $-\$ 201$ & $-\$ 282$ & $\$ 3$ & $\$ 224$ & $\$ 287$ & $\$ 119$ \\
\hline Non-major bleeding events & $-\$ 5$ & $-\$ 7$ & $-\$ 2$ & $\$ 1$ & $\$ 5$ & $\$ 1$ \\
\hline Total & $-\$ 332$ & $-\$ 664$ & $-\$ 151$ & $\$ 0$ & $\$ 135$ & $-\$ 63$ \\
\hline
\end{tabular}

ARISTOTLE apixaban for the reduction in stroke and other thromboembolic events in atrial fibrillation, $M B E H S$ major bleeding events excluding hemorrhagic stroke, $M I$ myocardial infarction, $N R$ not reported, $N V A F$ nonvalvular atrial fibrillation, $P E / D V T$ pulmonary embolism/deep vein thrombosis, $R E-L Y$ randomized evaluation of long-term anticoagulation therapy, ROCKET-AF rivaroxaban once daily oral direct factor Xa inhibition compared with vitamin $\mathrm{K}$ antagonism for prevention of stroke and embolism trial in atrial fibrillation

[10], non-major bleeding event $=\$ 130[8,14]$. In a year, overall medical cost differences associated with apixaban, dabigatran, and rivaroxaban use relative to warfarin among NVAF patients with $\mathrm{CHADS}_{2}=2$ were estimated at $-\$ 298,-\$ 143$, and $\$ 117$, respectively (negative numbers indicate cost reduction), and among those with $\mathrm{CHADS}_{2} \geq 3$ were estimated at $-\$ 697, \$ 2$, and $-\$ 100$, respectively (Table 2 ).

In the sensitivity analysis, in which rates of clinical events for warfarin were estimated as weighted averages from the three OAC trials 
and those of individual OACs as relative risks to the common warfarin event rates, overall medical cost differences associated with apixaban, dabigatran, and rivaroxaban use relative to warfarin among NVAF patients with $\mathrm{CHADS}_{2}=2$ were estimated at $-\$ 332,-\$ 151$, and $\$ 135$, respectively, and among those with $\mathrm{CHADS}_{2} \geq 3$ were estimated at $-\$ 664, \$ 0$, and -\$63, respectively (Table 3 ).

\section{DISCUSSION}

Differences in medical costs for OACs compared with warfarin are dependent on the specific OAC used and stroke risk. In this analysis, only apixaban use was associated with consistently reduced medical costs relative to warfarin for NVAF patients with moderate or high stroke risk. The primary drivers for medical cost reductions associated with apixaban use, relative to warfarin, were reduced rates of SSE, which were $14 \%$ and $32 \%$ lower, and MBEHS, which were $20 \%$ and $25 \%$ lower, for NVAF patients with $\mathrm{CHADS}_{2}=2$ and $\mathrm{CHADS}_{2} \geq 3$, respectively. The use of either dabigatran or rivaroxaban instead of warfarin was associated with lower risks for SSE, but not consistently lower risks for other clinical events and, therefore, their cost differences were less.

This analysis was based on clinical trial data and the application of the results to routine clinical practice requires further assessment. Since the occurrences of stroke and major bleeding events may be greater in routine clinical practice [15], the cost differences may have been underestimated. Additionally, when major bleeding events and HS relative rates were originally reported as hazard ratios, the analysis measured the relative risk of "time to first event" [5-7]. The subtraction approach used in this analysis did not consider any impact of timing and, thus, may have underestimated the rate of MBEHS.

\section{ACKNOWLEDGMENTS}

Editorial assistance was provided by Melissa Lingohr-Smith of Novosys Health and was funded by Bristol-Myers Squib and Pfizer. Sponsorship for this study and article processing charges were provided by BristolMyers Squibb and Pfizer. Steve Deitelzweig is the guarantor for this article, and takes responsibility for the integrity of the work as a whole.

Conflict of Interest. Steve Deitelzweig and Alpesh Amin were paid consultants for Novosys Health in connection with conducting this study. Yonghua Jing, Dinara Makenbaeva, and John Graham are employees of Bristol-Myers Squibb and own stock in the company. Daniel Wiederkehr is an employee of Pfizer and owns stock in the company. Jay Lin is an employee of Novosys Health, which received financial support from Bristol-Myers Squibb and Pfizer in connection with conducting this study and development of this manuscript.

Ethical standard. The authors conformed with the Helsinki Declaration of 1975, as revised in 2000 concerning human and animal rights. Springer's policy concerning informed consent has been followed.

Open Access. This article is distributed under the terms of the Creative Commons Attribution Noncommercial License which permits any noncommercial use, distribution, and reproduction in any medium, provided the original author(s) and the source are credited. 


\section{REFERENCES}

1. Go AS, Hylek EM, Phillips KA, et al. Prevalence of diagnosed atrial fibrillation in adults: national implications for rhythm management and stroke prevention: the Anticoagulation and Risk Factors in Atrial Fibrillation (ATRIA) study. JAMA. 2001;285: 2370-5.

2. Wolf PA, Abbott RD, Kannel WB. Atrial fibrillation as an independent risk factor for stroke: the Framingham Study. Stroke. 1991;22:983-8.

3. Ansell J, Hirsh J, Hylek E, Jacobson A, Crowther M, Palareti G; American College of Chest Physicians. Pharmacology and management of the vitamin $\mathrm{K}$ antagonists: American College of Chest Physicians evidence-based clinical practice guidelines (8th ed.). Chest. 2008;133:160S-98S.

4. Fustinoni $\mathrm{O}$. The case for an elderly targeted stroke management. Front Neurol. 2011;2:89.

5. Granger CB, Alexander JH, McMurray JJ, et al. Apixaban versus warfarin in patients with atrial fibrillation. N Engl J Med. 2011;365:981-2.

6. Connolly SJ, Ezekowitz MD, Yusuf S, et al. Dabigatran versus warfarin in patients with atrial fibrillation. N Engl J Med. 2009;361:1139-51.

7. Patel MR, Mahaffey KW, Garg J, et al. Rivaroxaban versus warfarin in nonvalvular atrial fibrillation. N Engl J Med. 2011;365:883-91.

8. Deitelzweig S, Amin A, Jing Y, et al. Medical cost reductions associated with the usage of novel oral anticoagulants vs. warfarin among atrial fibrillation patients, based on the RE-LY, ROCKET-AF and ARISTOTLE Trials. J Med Econ. 2012;15:776-85.

9. Consumer Price Index December 2010. Bureau of Labor Statistics US Department of Labor. Available at http://www.bls.gov/cpi/. Last accessed Aug 2011.

10. Mercaldi CJ, Ciarametaro M, Hahn B, et al. Cost efficiency of anticoagulation with warfarin to prevent stroke in medicare beneficiaries with nonvalvular atrial fibrillation. Stroke. 2011;42:112-8.

11. Sorensen SV, Kansal AR, Connolly S, et al. Costeffectiveness of dabigatran etexilate for the prevention of stroke and systemic embolism in atrial fibrillation: a Canadian payer perspective. Throm Haemost. 2011;105:908-19.

12. Earnshaw SR, Scheiman J, Fendrick AM, McDade C, Pignone M. Cost-utility of aspirin and proton pump inhibitors for primary prevention. Arch Intern Med. $2011 ; 171: 218-25$.

13. Spyropoulos AC, Lin J. Direct medical costs of venous thromboembolism and subsequent hospital readmission rates: an administrative claims analysis from 30 managed care organizations. J Manag Care Pharm. 2007;13:475-86.

14. Center for Medicare and Medicaid Services. Medicare fee schedule, payment and reimbursement benefit guideline: medicare fee schedule for office visit CPT codes-2011.

15. Hylek EM, Evans-Molina C, Shea C, Henault LE, Regan S. Major hemorrhage and tolerability of warfarin in the first year of therapy among elderly patients with atrial fibrillation. Circulation. 2007;115:2689-96. 